RESEARCH ARTICLE

Sokoto Journal of Veterinary Sciences
$\frac{\text { (P-ISSN 1595-093X/ E-ISSN 2315-6201) }}{\text { Waziri et al /Sokoto Journal of Veterinary Sciences (2017) 15(2): 49-53. }}$

\title{
Determination of gestational age through trans-abdominal scan of placentome diameter in Nigerian breed of sheep and goats
}

\author{
MA Waziri ${ }^{1}, A B$ Ikpe $^{1}$, MM Bukar $^{1 *}$ \& AY Ribadu ${ }^{2}$ \\ 1. Department of Theriogenology, Faculty of Veterinary Medicine, University of Maiduguri, Nigeria \\ 2. Sule Lamido University, Kafin Hausa, Jigawa, Nigeria
}

*Correspondence: Tel.: +2347066020816; E-mail: mmbukar@unimaid.edu.ng

\begin{abstract}
The usefulness of placentome diameter measurement for the determination of gestational age in Nigerian breed of sheep and goats was investigated in two experiments. In the first experiment, cross-sectional design was used and placentome diameters were measured in 18 Yankasa/Uda crossbred ewes and 20 Sahel does using transabdominal probe. A tentative estimate of gestation age was made using placentome diameter and gestation age correlates from a previous study. Subsequently, the date of parturition was recorded for each animal and the actual conception date was calculated retrospectively using a previously described 148-day gestation table for ewes and does. In the second experiment, a prospective cohort design was used on 6 goats, from end of second trimester until parturition. The date of conception was then retrospectively calculated. It was found that the estimated and actual gestation ages in both sheep and goats were not significantly different $(P>0.05)$. The correlation coefficient $\left(r^{2}\right)$ between the placentome diameter and gestation age was $0.84(P=0.0001)$, for sheep and $0.90(P=0.0001)$ for goats suggesting a significant high positive correlation between placentome diameter and gestational age. The regression equation was $y=2.809 x+7.555$ and $y=2.930 x+9.611$ for sheep and goats, respectively. However, the placentome diameters monitored until parturition were not significantly different $(P>0.05)$ between the weeks and not significantly correlated with gestational age. It was concluded that placentome diameter is useful to estimate gestational age at mid gestation and not within the last third of pregnancy.
\end{abstract}

Keywords: Gestational age, Goat, Placentome diameter, Sheep, Ultrasonography

Received: 06-12- 2016

Accepted: 24-03-2017

\section{Introduction}

In Nigeria, sheep and goats provide their owners with meat, skin, milk, as well as source of investment and insura nce against crop failure (Devendra \& Solaiman, 2010). In most flocks of sheep and goats, natural service dates are unobserved or unrecorded, hence a reliable, non-invasive, fast, and reproducible method for diagnosis of pregnancy is essential (Doize et al., 1997).

Real time B-mode ultrasonography is an accurate, rapid and safe method for diagnosing pregnancy in small ruminants with nearly $100 \%$ accuracy (Garcia et al., 1993; Doize et al., 1997). The use of several measurable objective variables such as the size of fetal head (bi-parietal diameter), thoracic depth and embryo length (size) among others have been described in determination of gestational age by ultrasonography in small ruminants (Sergeev et al., 1990; Reichle \& Haibel, 1991).

Another measurable variable are the placentomes (Adeyinka et al., 2014; Petrujkic et al., 2016) which are readily observable via trans-abdominal ultrasonography throughout pregnancy in small ruminants (Bretzlaff et al., 1993; Doize et al., 1997). They are readily imaged in cross-section as cup- 
shaped hyper-echogenic structures with concave surface directed towards the uterine lumen (Haibel, 1990). In addition, Lawrence et al. (2016) suggested that correlation between placentome size and gestational age can be improved by increasing the number of placentomes measured. Furthermore, due to variations in breed and nutrition among different management systems, it is important for each breed to be assessed for the information to be relevant and applicable to the target population of sheep and goats. Thus, the objective of this study was to determine the usefulness of placentome diameter measurement for the determination of gestational age during mid-gestation in crossbred Yankasa/Uda ewes and Sahel does.

\section{Materials and Methods}

Animals and management

Two experiments were conducted on pregnant crossbred Yankasa/Uda ewes and Sahel does aged between 1.5 and 2.5 years. The animals were obtained from livestock farmers in Maiduguri, Nigeria, using purposive sampling technique. Only pluriparous animals that stood to be mated by males and did not return to oestrus were included in the study. The age of the animals were estimated through dentition as described by Dyce et al. (1987). Their body condition score was 3 on a scale of 1 to 5 (Burkholder, 2000). All the animals were acclimatized for 6 weeks in a semi-intensive management system where they roamed freely in the day time. They were fed supplements (mainly groundnuts hay, beans and corn husk) in the mornings and evenings and water was provided ad libitum.

\section{Animal preparation and procedure for scanning}

The animals were approximately in mid-gestation at the commencement of the experiments. All the animals used in this study were restrained in a natural standing position and the ultrasound examination for pregnancy was conducted as described by Hesselink \& Taverne (1994), with modifications of not fasting and shaving according to
Kahn (2004). A real-time ultrasound scanner EMP820Vet (Model: vet image 201 with a serial No. 20101220), Recorders and Medicare Systems (RMS) LTD. fitted with $5.0 \mathrm{MHz}$ convex array transducer (Probe Model: C080-60F) was used. The probe had a $60 \mathrm{~mm}$ radius, $190 \mathrm{~mm}$ scanning scope and $60^{\circ}$ angle. Carboxymethylcellulose ultrasound transmission gel (BEGOODSONIC1000 ${ }^{\circledR}$ ) was used as coupling medium. The probe was applied to the hairless area immediately cranial to the udder as described by Kahn (2004).

\section{Experimental design}

In the first experiment, a total of 18 ewes and 20 does were used. The placentome diameters were measured in the pregnant animals and the average measurements of three largest placentomes for each ewe and doe were recorded as described by Lawrence et al. (2016). The gestation age was estimated using placentome diameter lengths recorded from a previous abattoir-based study (Waziri et al., 2009).

Each ewe and doe was monitored and the date of parturition was recorded. The conception date was calculated retrospectively, based on 148-day gestation period using the date of delivery described by Gimenez \& Rodning (2007). Using the determined conception date, the actual gestation age of the recorded placentome diameters was determined.

In the second experiment, 6 pregnant Sahel does were used in a prospective cohort design. Transabdominal scanning and measurement of placentome diameter was done once a week until parturition. Three placentomes were measured for each doe as was done in the first experiment. After parturition, the actual conception date was calculated retrospectively according to Gimenez \& Rodning (2007), and the data obtained was realigned to the retrospective week of conception. Parturition occurred in all the does within 9 weeks of commencement of the study and placentome diameter measurements for the last 7 weeks prepartum were obtained in all 6 does and aligned to actual gestation age (week). Student t test was used

Table 1: Mean \pm SD of the estimated and actual time to parturition (days) in sheep and goats

\begin{tabular}{cllc}
\hline \multicolumn{1}{c}{ Animals } & $\begin{array}{l}\text { Estimated } \\
\text { Gestation }\end{array}$ & $\begin{array}{l}\text { Actual } \\
\text { gestation }\end{array}$ & $\begin{array}{l}\text { P-value } \\
\text { (Paired T-test) }\end{array}$ \\
\cline { 2 - 4 } Sheep $(n=18)$ & $78.5 \pm 14.6$ & $77.3 \pm 20.5$ & 0.571 \\
Goats $(n=20)$ & $82.2 \pm 19.3$ & $82.8 \pm 23.1$ & 0.735 \\
\hline
\end{tabular}

Means are significantly different at $\mathrm{P}<0.05$

to compare the estimated and actual gestational age recorded in experiment 1 . One-way Analysis of
Variance and linear regression were carried out on the data obtained in experiment 2. GraphPad (2003) 
was employed for the data analyses. Results were presented in Tables and Figures.

\section{Results}

The estimated and actual time to parturition in both sheep and goats were not significantly different $(P>0.05)$ as shown in Table 1 . The placentome diameter during the last 7 weeks of gestation until parturition in goat is shown in Table 2. The placentome diameter was not significantly different $(P>0.05)$ between the weeks until parturition.

Plate 1 shows the placentomes being measured with the ultrasound's built in callipers. Figure 1 shows the trend and relationship of placentome diameter measurements and the estimated gestation age with the actual gestation age in sheep. The regression was significantly different $(F=202.06 ; P=0.0001)$. The coefficient of determination $\left(r^{2}\right)$ was 0.84 , while Figure 2 shows a similar trend and relationship in goats. For the goat, the regression was also significantly different $(F=314.21 ; P=0.0001)$, with even higher $r^{2}$ of 0.90 . The regression equations were: $y=2.809 x+7.555$ and $y=2.930 x+$ 9.611 for sheep and goats, respectively.

Result from the second experiment showed that mean placentome diameter measured weekly for the last 7 weeks before parturition was not significantly different ( $P>0.05)$ with each other. Furthermore, placentome diameter monitored until parturition was not significantly correlated with gestational age.

Table 2: Placentome diameter during the last 7 weeks of gestation until parturition in goats

\begin{tabular}{cccc}
\hline \multirow{2}{*}{$\begin{array}{c}\text { Week of gestation } \\
\text { until parturition }\end{array}$} & \multicolumn{3}{c}{ Placentome Diameter $(\mathrm{mm})$} \\
\cline { 2 - 4 } & Mean \pm SD & Minimum & Maximum \\
\hline 7 & $25.9 \pm 4.5$ & 20.8 & 35.1 \\
5 & $24.4 \pm 4.9$ & 16.6 & 32.4 \\
4 & $26.0 \pm 3.5$ & 20.0 & 31.5 \\
3 & $25.8 \pm 3.0$ & 21.3 & 31.4 \\
2 & $26.3 \pm 3.7$ & 19.1 & 33.3 \\
1 (parturition) & $23.2 \pm 2.8$ & 19.4 & 28.7 \\
\hline
\end{tabular}

Means in columns were not significantly different $(P>0.05)$

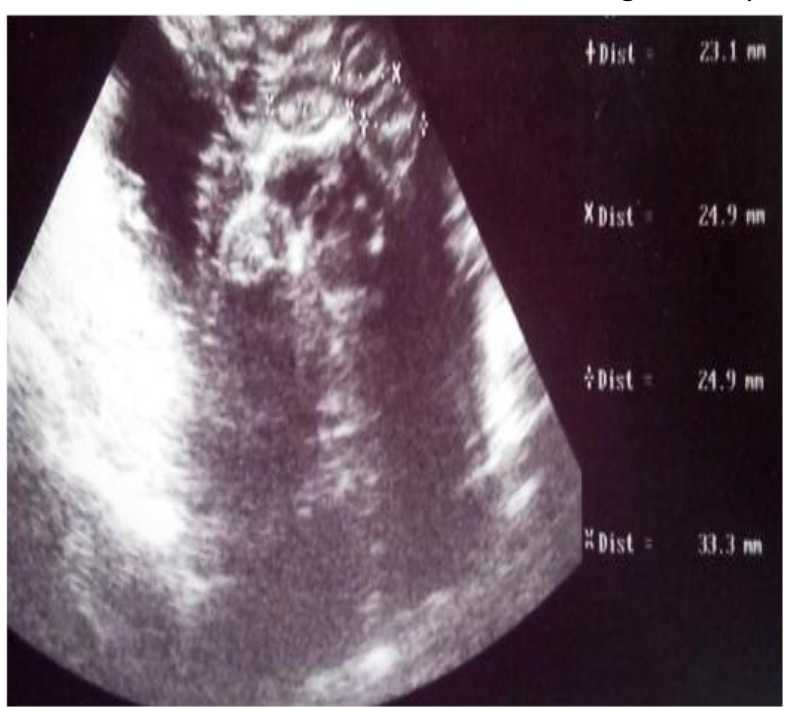

Plate I: Sonogram of a pregnant goat showing the diameters $(\mathrm{mm})$ of four placentomes

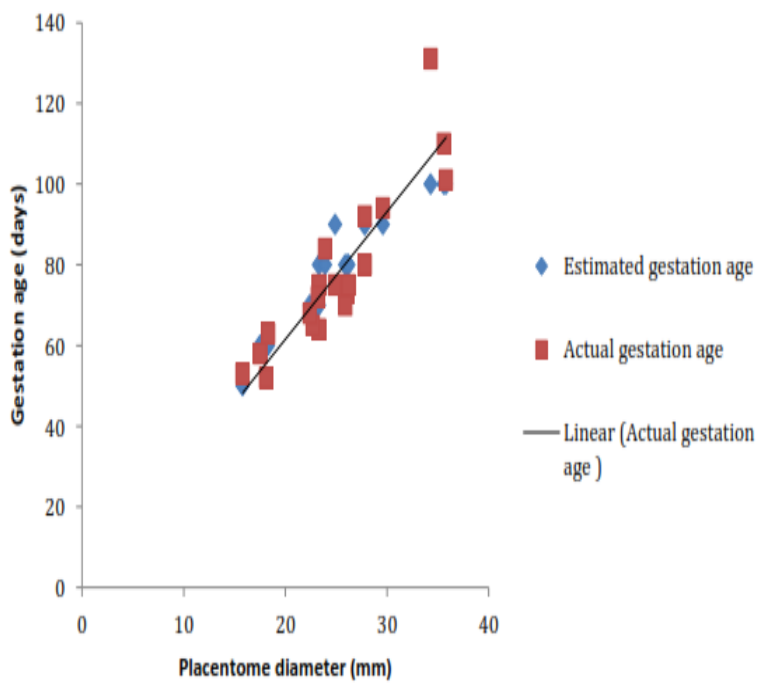

Figure 1: Scatter plot of placentome diameter $(\mathrm{mm})$ and gestational age (days) of sheep showing a linear trend for actual gestation age 


\section{Discussion}

The relationship between placentome diameter and gestation age of sheep and goats found in the current study agreed with previous studies which were conducted with gross anatomic specimens (Doize et al., 1997; Waziri et al., 2009). However in sheep, the high correlation between gestation age and placentome size $\left(r^{2}=0.84\right)$ disagrees with the reports of Doize et al. (1997) who observed poor correlation of $\left(r^{2}=0.15\right)$ in ewes, although they found significant positive correlation for does $\left(r^{2}=0.7\right)$. According to Doize et al. (1997), placentome size increased rapidly during the first 70 to $90 \mathrm{~d}$ of gestation in ewes and does.

In goats, the high positive correlation between gestation age and placentome diameter observed in the present study was similar to the findings of Leigh \& Fayemi (2010) which was $r^{2}=0.94$. On the other hand, other workers, reported lower correlation with $r^{2}$ ranging from 0.45 to 0.57 (Lee et al., 2005; Nwaogu et al., 2010). These differences might be due to the goat breeds studied and the technique of placentome measurements. In the present study, average diameter of three placentomes was used to estimate the age of gestation. In addition, our estimation of the gestation age was not significantly different from the actual gestation age in goats. This could be explained with the report of Igwebuike \& Ezeasor (2013), which observed that the average size of the placentome in West African dwarf does increased linearly $\left(r^{2}=0.978 ; P<0.05\right)$ as pregnancy progressed.

In the second study, it was found that there was no significant correlation between placentome diameter and the stage of gestation. This suggests that while the gestation age could be estimated at mid gestation as seen in the first experiment, the placentome diameter is not a good indicator of gestational age during the last third of pregnancy. According to Adeyinka et al. (2014), there was a significant association between placentome size and gestational age in cows, but between-cow variation in placentome size and growth resulted in poor

\section{References}

Adeyinka FD, Laven RA, Lawrence KE, van Den Bosch M, Blankenvoorde G \& Parkinson TJ (2014). Association between placentome size, measured using transrectal ultrasonography, and gestational age in cattle. The New Zealand Veterinary Journal, 62(2): 51-56.

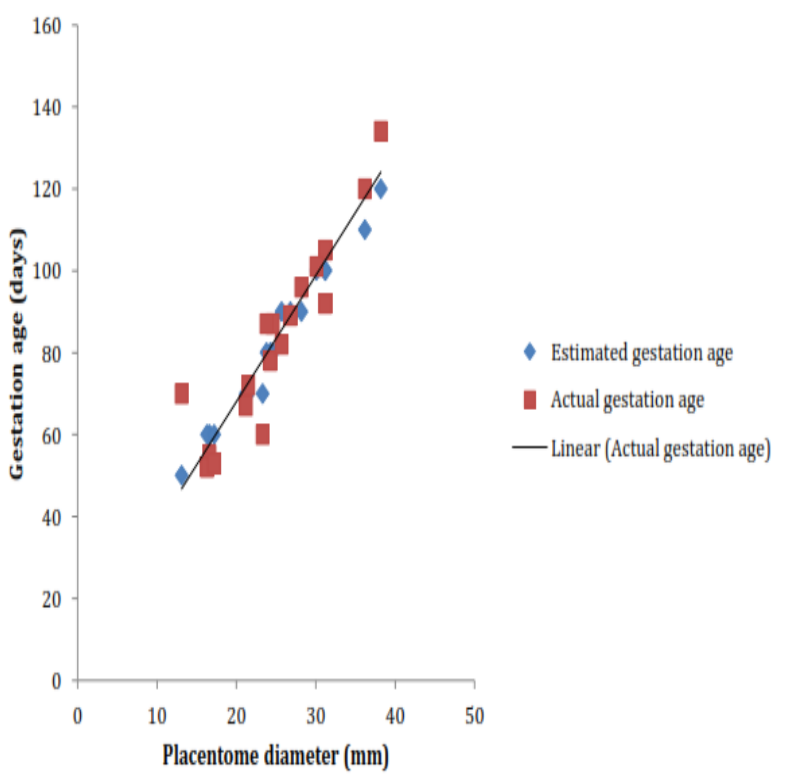

Figure 2: Scatter plot of placentome diameter $(\mathrm{mm})$ and gestational age (days) of goats showing a linear trend for actual gestation age

agreement between placentome size and gestational age, hence, they recommended that mean placentome size should not be used to estimate gestational age. In the current study, no significant difference was observed between placentome diameters measured weekly during the last 7 weeks of gestation. This suggests that average placentome diameter remained the same in the last weeks before parturition. This, along with variations in placentome diameter between does and variation in the individual placentome measured would explain the lack of usefulness of placentome diameter to estimate gestational age in the last third of gestation/pregnancy.

In conclusion, placentome diameter measurement is useful in determining gestational age at midgestation but may not be accurate during the last 7 weeks of gestation. Thus, it is suggested that accurate determination of gestational age could be increased by measurement of other available foetal parameters.

Bretzlaff K, Edwards J, Forrest D \& Nuti L (1993). Ultrasonographic determination of pregnancy in small ruminants. Veterinary Medicine, 88: 12-24.

Burkholder WJ (2000). Use of body condition scores in clinical assessment of the provision of optimal nutrition. Journal of the American 
Veterinary Medical Association, 217(5): 650654.

Devendra C \& Solaiman SG (2010). Perspectives on Goats and Global Production. In: Goat Science and Production (SG Solaiman editor), first edition, Blackwell Publishing. lowa. Pp 3-20.

Doize F, Vaillancourt D, Carabin H \& Belanger D (1997). Determination of gestational age in sheep and goats using transrectal ultrasonographic measurement of placentomes. Theriogenology, 48(3): 449460.

Dyce KM, Sack WB \& Wensing GTH (1987). Textbook of Veterinary Anatomy, first edition. WB Saunders Co., Philadelphia. Pp 675.

Garcia A, Neary MK, Kelly GR \& Pierson RA (1993). Accuracy of ultrasonography in early pregnancy diagnosis in the ewe. Theriogenology, 39(4): 847--861.

Gimenez D \& Rodning S (2007). Reproductive Management of Sheep and Goats. Alabama Cooperative Extention. System (ACES), http://www.aces.edu/pubs/docs/A/ANR1316/ANR-1316.pdf, retrieved 16-06- 2014.

Graphpad (2003). InStat guide to choosing and Interpreting Statistical Tests. San Diego 912130, California, USA: GraphPad Software Inc. 11452, 215.

Haibel GK (1990). Use of ultrasonography in reproductive management of sheep and goat herds. Veterinary Clinics of North America, 6(3): 597-613.

Hesselink JW \& Taverne MA (1994). Ultrasonography of the uterus of the goat. Veterinary Quaterly, 16(1): 41-45.

Igwebuike UM \& Ezeasor DN (2013). The morphology of placentomes and formation of chorionic villous trees in West African Dwarf goats (Capra hircus). Veterinarski Arhiv, 83(3): 313-321.

Kahn W (2004). Ultrasonography in sheep and goats. In: Veterinary Reproductive Ultrasonography, Schlutersche
Verlagsgesellschaft GmbH \& Co., HansBockler-Allee, Hannover. Pp 187- 210.

Lawrence KE, Adeyinka FD, Laven RA \& Jones G (2016). Assessment of the accuracy of estimation of gestational age in cattle from placentome size using inverse regression. The New Zealand Veterinary Journal, 9(4): 1-5.

Lee $Y$, Lee $P$, Cho J, Shin $H$, Choi $Y$, Shin $Y$, Choi W, Shin H, Lee D, Lee G \& Shin S (2005). Ultrasonic measurements of fetal parameters for estimation of gestational age in Korean black goats. Journal of Veterinary Medical Science, 67(5): 497-502.

Leigh OO \& Fayemi OE (2010). Estimation of gestational age using ultrasonic measurement of fetal parameters in West African Dwarf goat. Tropical Veterinarian, 28(2): 43-49.

Nwaogu IC, Anya KO \& Agada PC (2010). Estimation of foetal age using ultrasonic measurements of different foetal parameters in red Sokoto goats (Capra hircus). Veterinarski Arhiv, 80(2): 225-233.

Petrujkic BT, Cojkic A, Petrujkic K, Jeremic I, Masulovic D, Dimitrijevic V, Savic M, Pesic M \& Beier RC (2016). Transabdominal and transrectal ultrasonography of fetuses in Wurttemberg ewes: Correlation with gestational age. Animal Science Journal, 87(2): 197-201.

Reichle JK \& Haibel GK (1991). Ultrasonographic biparietal diameter of second trimester pygmy goat foetuses. Theriogenology, 35(4): 689-695.

Sergeev L, Kleeman DO, Walker SK, Smith DH, Grosser TI, Mann T \& Seamark RF (1990). Real time ultrasound imaging for predicting ovine foetal age. Theriogenology, 34(3): 593-601.

Waziri MA, Sivachelvan N \& Ribadu AY (2009). The sequential gross and histological changes of the placenta of the sahel goats. Nigerian Veterinary Journal, 30(2): 16-23. 